\title{
Effect of environmental conditions on accumulation of some pharmaceutical substances in Calotropis procera
}

\author{
Saeed Baabad ${ }^{1}$, Hani M. Ali ${ }^{1}$, Thana Khan ${ }^{1}$ and Ahmed M Ramadan ${ }^{1,2}$ \\ ${ }^{1}$ Biological Sciences Department, Faculty of Science, King Abdulaziz University, Jeddah, Saudi Arabia \\ ${ }^{2}$ Department, Agricultural Genetic Engineering Research Institute (AGERI), Agriculture Research Center (ARC), Giza, Egypt
}

Correspondence Author: Ahmed M Ramadan, Biological Sciences Department, Faculty of Science, King Abdulaziz University, Jeddah, Saudi Arabia ${ }^{2}$ Department, Agricultural Genetic Engineering Research Institute (AGERI), Agriculture Research Center (ARC), Giza, Egypt

Received date: 12 August 2018, Accepted date: 10 December 2018, Online date: 25 December 2018

Copyright: (C) 2018 Saeed Baabad et al., This is an open-access article distributed under the terms of the Creative Commons Attribution License, which permits unrestricted use, distribution, and reproduction in any medium, provided the original author and source are credited.

\begin{abstract}
Calotropis procera, is found in many different zones or habitats and known for being a source of secondary metabolites (ex., glycosides, alkaloids, terpenoids) which contain pharmaceutical compounds used in treatment of many diseases. Our study aims to identify the suitable day light period for high accumulation of pharmaceutical compounds and the effect of irrigation on their concentrations in Calotropis procera. In this study, using UPLC/MS/MS separation, concentration variation in very important three of glycosides - which have medical effects- was detected and observed under the environmental conditions (light- irrigation). These compounds were Calotoxin, $\alpha$-amyrene and Uzarigenin. Also, the suitable time for these pharmaceutical compounds accumulation in high concentrations was detected and we found that it was variable depending on compound types. Uzarigenin di glycoside concentration was significantly highly accumulated at midday before irrigation (M) but was the lowest at pre-dusk after irrigation (iPD). However, Uzarigenin accumulation was highly significant at all time except dawn before irrigation (D). Also, $\alpha$-amyrene accumulation, - was highly significant at all time except dawn after irrigation (iD), as it was the lowest. Calotoxin 1 was observed only at predusk before irrigation (PD). Using bioinformatics tools and RNA-seq data, four genes related to pharmaceutical compound production in Calotropis plant were identified; flavonol oxygenase (accession no. KU997644), oxysterolbinding protein (accession no. KX002269), calreticulin (accession no. KT943752) and amyrine synthase (accession no. KU997645). This study helps to determine the quality and quantity of some pharmaceutical compounds in Calotropis procera, as well as the appropriate time to isolate a huge quantity of these components.
\end{abstract}

Key words: Calortopis procera, pharmaceutical, Uzarigenin, $\alpha$-amyrene, Calotoxin

\section{INTRODUCTION}

Calotropis procera is a flowering plant in the poison family, Apocynacae, natively grows in North Africa, Tropical Africa, Western Asia, South Asia, and Indochina [1]. The commonly name in Saudi Arabia is Oshar. The plant grows in dry areas. Most research concerning Calotropis concentrated on its medicinal properties [2] [3] as an important source of pharmaceutical compounds [4] [5]. Calotropis tissues, especially the root phloem, were heavily used in traditional medicine to treat leprosy, fever, menorrhagia, malaria, and snake bite. However, it contains a very toxic latex that causes blisters and rash [6]. Also, the extract of stem endophytes was used as antibacterial and colon cancer treatment [7]. Silky hairs of this plant were used to stuff pillows treatment [8]. Extracts and latex have shown high effects as nematicides, in vitro and in vivo [9] [10]. Phytochemical studies on this plant concluded several types of compounds such as Cardenolide, triterpinoids, alkaloids, resins, anthocyanins and proteolytic enzymes in latex, flavonoids, tannins, sterol, saponins, cardiac glycosides [11] [12] [13]. The leaves contain mainly the alpha amyrine and alpha amyrine acetate [14] $\beta$-sitosterol [15] [16], urosolic acid [17] [18], cardenolides, calotropin and calotropagenin [19]. The latex contains calotropin, calotoxin $0.15 \%$, calactin $0.15 \%$, uscharin $0.45 \%$, trypsin, voruscharin, uzarigenin, syriogenin and proceroside [20] [21]. The metabolome analysis in this plant has become the target to a lot of investigators either in treatment conditions [22] or as standard condition [23]. Many reports have confirmed that the previous compound possess several biological activities such as proteolytic [24], antimicrobial [25], larvicidal [26], nematocidal [27], anticancer [28] [29], anti-inflammatory [30] digestive and tonic properties. On the contrary, the powdered root bark has been reported to give relief in diarrhea and dysentery. Also, cysteine proteases which exhibit high thermo-stability and broad pH optima were isolated and characterized in this plant, and plasma-clotting activity [31]. It is important to identify genes involved in pharmaceutical compounds accumulation because this could facilitate the production of these compounds in-vitro in huge amount. Transcriptome analysis was used to identify most of genes involved in secondary metabolites pathways. Our study aimed to maximize the production of pharmaceutical compound in this plant specially glycosides and detect the suitable time to isolate this substance under light and watering conditions. In addition, identify and characterize genes involved in pharmaceutical substances accumulation in order to utilize the production of these compounds in another organism via genetic engineering approaches.

\section{Plant material}

\section{MATERIALS AND METHODS}

The samples were collected from three locations. Region 1 , in the north of Jeddah near Thole, Latitude $22^{\circ} 16^{\prime} 49.55$ and Longitude $39^{\circ} 7^{\prime} 28.18$. Region 2 , in the east of Jeddah near Al-Taef Region, Latitude $21^{\circ} 20^{\prime} 3.68$ and Longitude $40^{\circ} 12^{\prime} 4.04$. Region 3 , in 100 km south of Jeddah near Allyth Region, Latitude $20^{\circ} 20^{\prime} 11.49$ and Longitude $40^{\circ} 5^{\prime} 7.09$. 
In this area, Calotropis procera shrubs grow as single plants. The experiment was conducted according to [22], three time points (at dawn, at midday and one-hour pre-dusk) before and after irrigation. We also checked the area to be watered and figured, it was $1 \mathrm{~m}^{2}$. Then, plot edges were raised to avoid water flowing away and watering was done gradually. It was important to use distilled water to avoid adding impurities that might influence the indigenous microbial community (e.g. stimulants - trace organics; inhibitors - hypochlorite), and also to avoid adding water-borne microbes that might escalate through phloem to plant leaves and interfere with the metabolic content of the cells. RNA and metabolomic samples were collected at dawn (D), at midday (M) and one-hour pre-dusk (PD) before and after water treatment.

\section{Chromatography experiment}

The plant samples were dried at $70{ }^{\circ} \mathrm{C}$ for 12 hours. Extraction and chromatography analysis were performed according to [32]. The candidate precursors and daughter ions are illustrated in table 1.

The precursor (glycosides) MWs were calculated by sum the aglycone MW plus $163[(180-18)+1]$; where 180 is the sugar MW, 18 is the lost water molecule, 1 is the acquired proton from the LC/MS ionization. The daughter ions were calculated from the aglycone moiety plus one proton $(\mathrm{M}+\mathrm{H})$ and the aglycone minus hydroxyl group plus proton $(\mathrm{M}+\mathrm{H}-17)$ for all aglycones in addition to the daughter ion minus carbonyl group plus proton (M+H -28$)$ for the aglycones that contain carbonyl group (Table 1). The glycosides were calculated from the peaks area (Table 2).

Table 1. Molecular weights of selected aglycones, precursors and daughter ions detected by MRM mode of the LC/MS/MS analysis.

\begin{tabular}{|c|c|c|c|c|c|c|c|}
\hline \multirow{2}{*}{ Ser. } & \multirow{2}{*}{ Rt. } & \multirow{2}{*}{ Aglycone } & \multirow{2}{*}{ MW } & \multirow{2}{*}{ Glycoside Precursor } & \multicolumn{3}{|c|}{ Daughter ions } \\
\hline & & & & & $\mathbf{M}+\mathbf{H}$ & M-16 & M-27 \\
\hline 1 & 4.4 & Calotoxin (1) & 548.6 & 712 & 549 & 532 & 523 \\
\hline 2 & 10.3 & Calotoxin (2) & 548.6 & 712 & 549 & 532 & 523 \\
\hline 3 & 17.9 & Uzarigenin & 374.5 & 699 (di-glycoside) & 375 & 358 & --- \\
\hline 4 & 18.1 & Uzarigenin & 374.5 & 537 (mono-glycoside) & 375 & 358 & --- \\
\hline 5 & 18.1 & Calotoxin (3) & 548.6 & 712 & 549 & 532 & 523 \\
\hline 6 & 18.6 & $\alpha$-amyrene & 426.7 & 589 & 427 & 410 & --- \\
\hline 7 & ND & Calactin & 532.6 & 696 & 533 & 516 & $\begin{array}{ll}-- \\
--\end{array}$ \\
\hline 8 & ND & Uscharidin & 530.6 & 694 & 531 & 514 & --- \\
\hline
\end{tabular}

Statistical analysis

Statistical analysis was done by using SPSS program (One-way ANOVA with post-hoc Tukey HSD test)

\section{Gene detection and identification}

\section{Total RNA isolation}

Total RNA of $50 \mathrm{mg}$ tissue was extracted according to [33]. The RNA concentration was optimized by measuring the optical density at $260 \mathrm{~nm}$ and then calculated by the following equation; RNA concentration $(\mathrm{mg} / \mathrm{mL})=\mathrm{OD} 260 * 40 *$ dilution factor. RNA samples were sent to Beijing Genomics Institute $(\mathrm{BGI})$, Shenzhen, China for sequencing.

\section{NGS sequence}

Recovered RNA-seq reads were de-novo assembled and analyzed using Trinity RNA-Seq assembly package (version r2013-2-25) and the tuxedo suite software package. Reads were overlaped together to form contiguous sequence fragments called contigs based on the de Bruijn graph algorithm. Contigs were assembled at k-mer value $=50$ and collected into transcripts to get full length genes. Then, the relative abundance of transcripts was estimated using RSEM (v1.1.6). Five gene sequences were compared with other plant species from the GenBank and used as a reference for blasting.

\section{Determination of phylogenetic relationships}

The maximum-likelihood method) was used to build a dendrogram using CLC Genomics Workbench. A bootstrap value is indicating the confidence level in this branch.

\section{NCBI submission}

The produced genes were submitted to NCBI under the following accession numbers: flavonol oxygenase (accession no. KU997644), oxysterol-binding protein (accession no. KX002269), calreticulin (accession no. KT943752), Amyrine synthase (accession no. KU997645).

\section{Chromatography (LC/MS/MS)}

\section{RESULT AND DISCUSSIONS}

The LC/MS/MS analysis clarified the presence of two groups of glycosides (fig.1A). The same two groups were also appeared in the MRM total ion chromatogram (TIC-MRM chromatogram) (fig. 1B) that confirms the presence of the selected glycosides. The MRM chromatograms of 7 detected glycosides and its own glycone daughter ion was illustrated (Figures 2-6).

The most abundant daughter ion for some glycosides such uzarigenin was $\mathrm{M}-17+\mathrm{H}$ (fig. 3). This is due to lose of the hydroxyl group from the aglycone molecule followed by acquiring a proton.

$\alpha$-amyrene, Uzarigenin accumulation was highly significant at all time except dawn after irrigation (iD), as it was the lowest (Table 2). Calotoxin1 showed only in pre-dusk before irrigation (PD).

Cardiac glycosides are observed among different genera of Apocynaceae [32]. It has a role in plant defense system [34]. Mechanical wounding enhances these chemical defense of plants [35]. Cardenolide accumulation was enhanced after mechanical wounding in Calotropis gigantea hairy root culture [36] and calotropis procera [23]. Cardiac glycosides accumulation includes Uscharidin, Calactin, Frugoside, Uscharin, Asclepin, Uzarigenin, Coroglaucigenin and Calotropagenin were studied in-vitro across developmental stages of plant and different parts (stem, leaf and root) [23], they found that the highest concentration of cardiac glycosides was in three months old seedling and the variation of accumulation in plant parts depends on compound types. In our study, we focused on light effect before and after watering this plant in wild environment and we selected plant leaves (the most sensitive part in plant to light). Our foundation is adding new information in cardiac glycosides accumulation in Calotropis procera. Although, we detected the light effect on accumulation of three compounds (Calotoxin, $\alpha$-amyrene, and Uzarigeni), one of them was in two forms (Uzarigenin). As a result, we can add light and watering to previous factors that significantly affect pharmaceutical compound accumulation in Calotropis procera. 


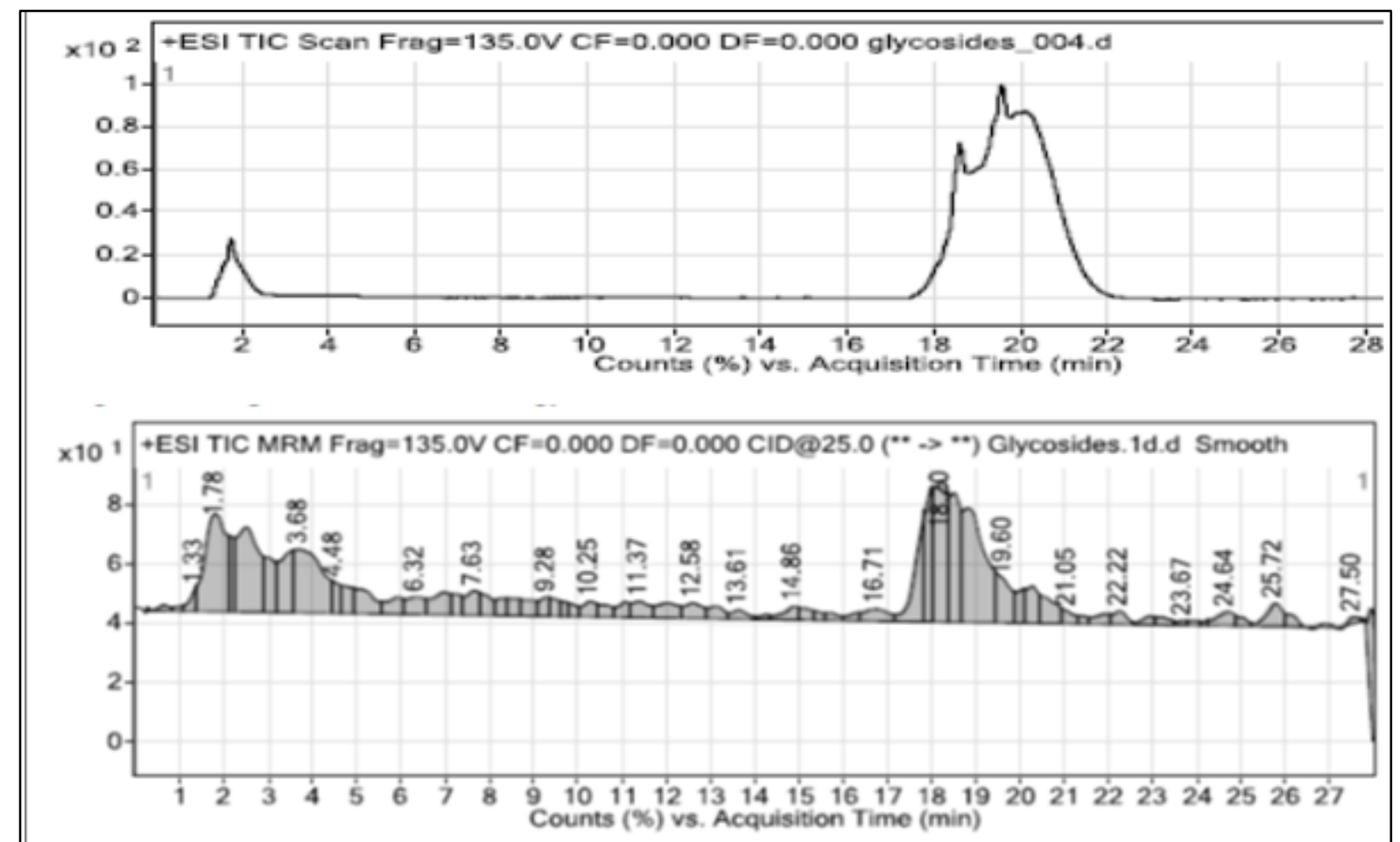

Fig. 1: The total ion chromatogram (TIC) of glycosides analyzed by LC/MS/MS by the scan mode (A) and MRM (B) techniques showed two groups of glycosides. The compound names were explained in Table 1.

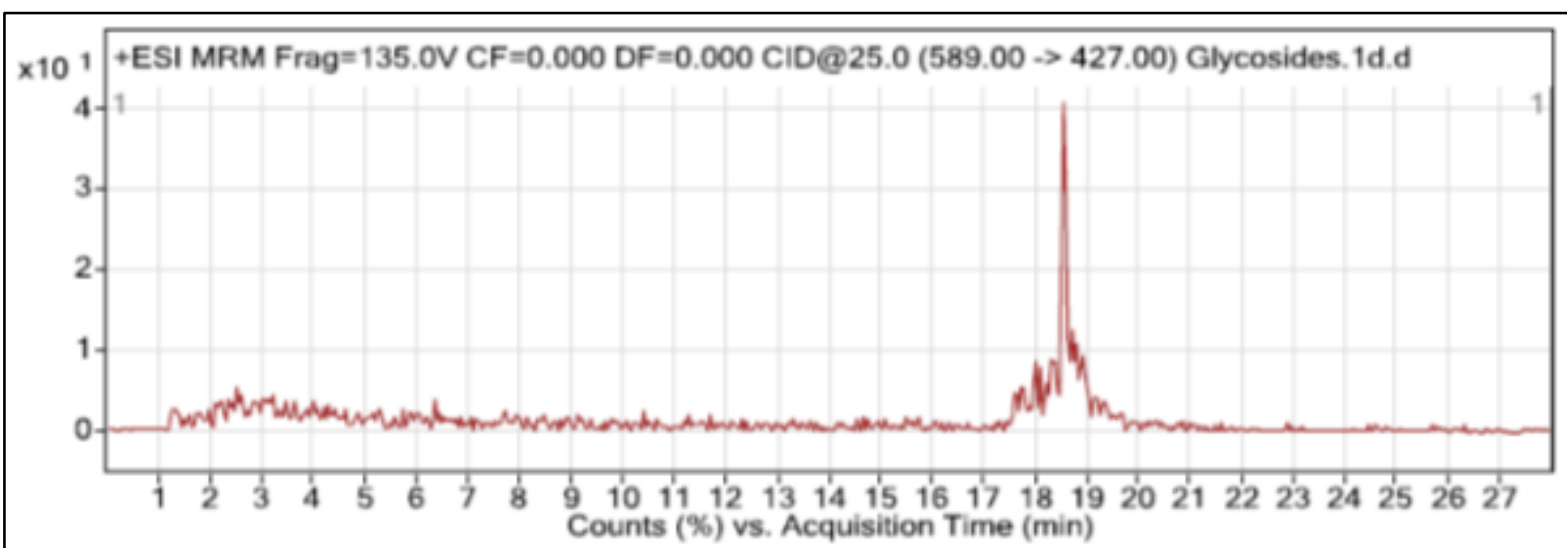

Fig. 2: The $\alpha$-amyrene glycoside (Rt. 18.6 min., precursor 589 , daughter ion 427 )

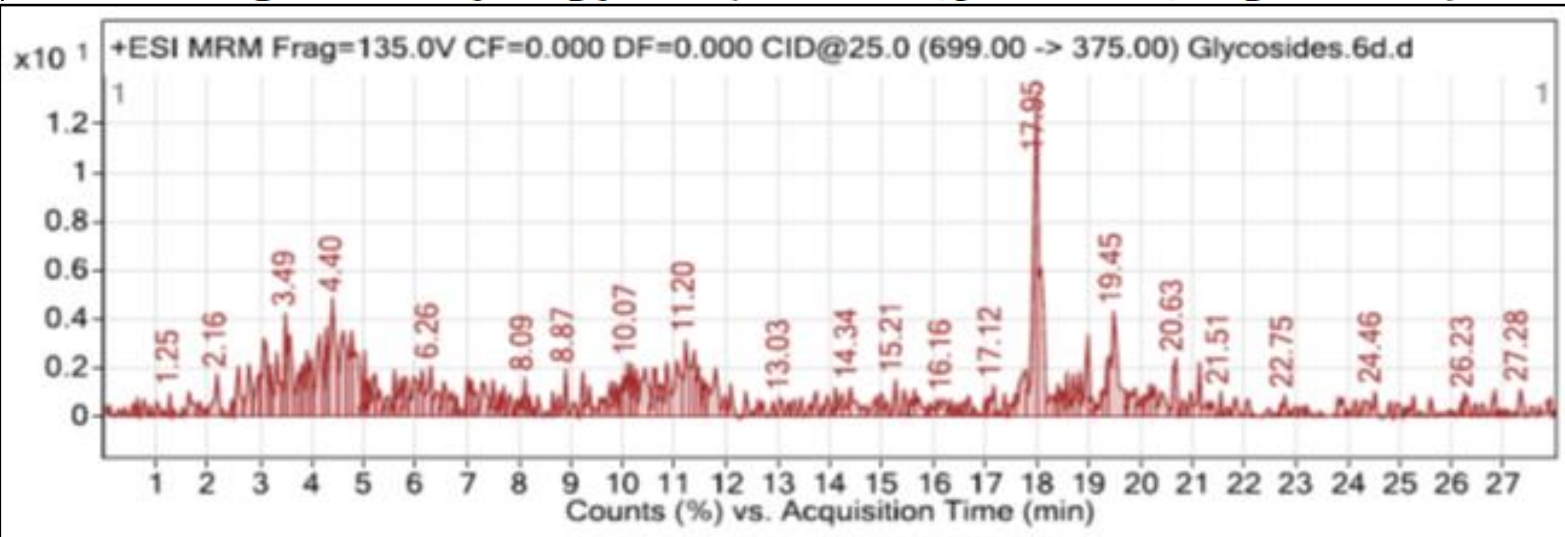

Fig. 3. The Uzarigenin di-glycoside (Rt. 17.9 min. precursor 699, daughter ion 375). 


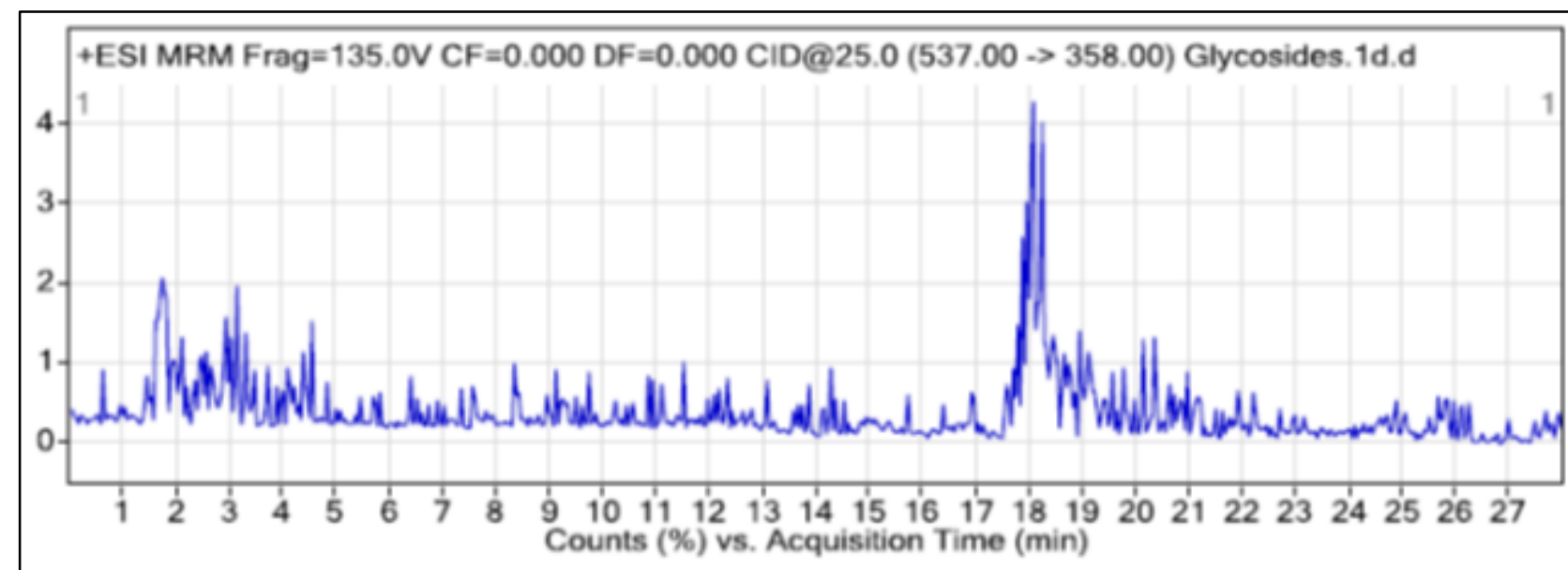

Fig. 4. The Uzarigenin glycoside (Rt. 18.1 min. precursor 537, daughter ion 358).

Table 2. Effect of light before and after irrigation treatments on peaks area of glycosides concentrations percentage in Calotropis procera. Dawn (D), midday (M), pre-dusk (PD), dawn after irrigation (iD), midday after irrigation (iM) and pre-dusk after irrigation (iPD)

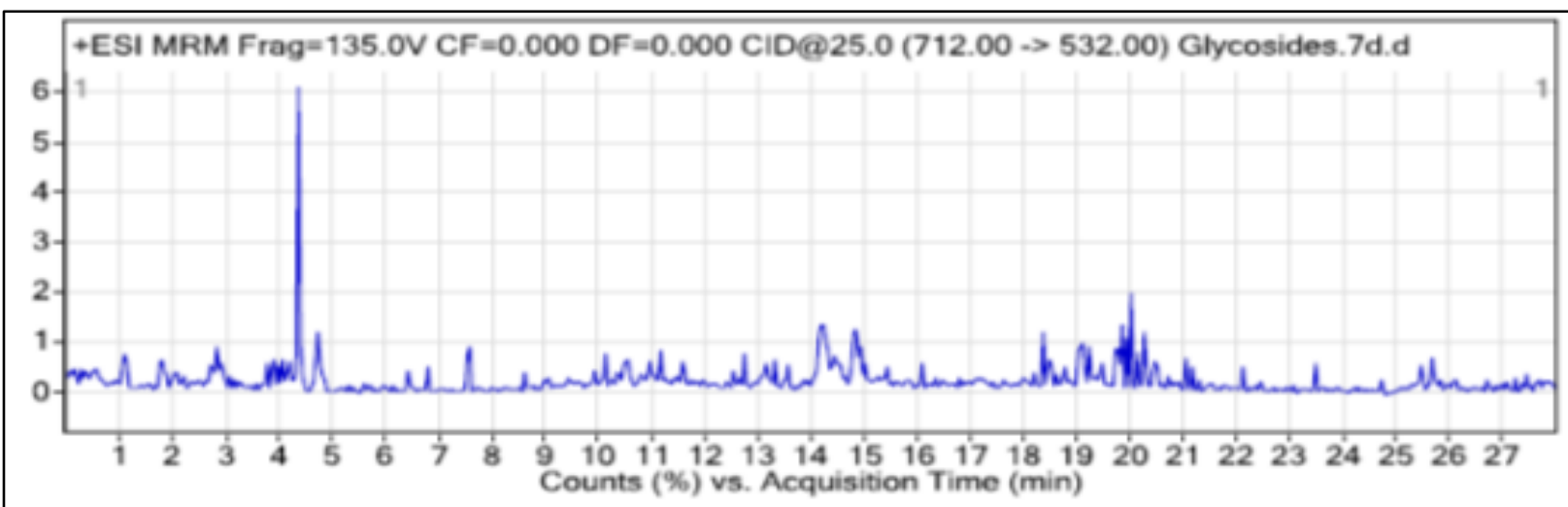

Fig. 5. MRM chromatogram for calotoxin glycoside (MW 712), Rt. 4.4 min., daughter ion 532. $\alpha$-amyrene

\begin{tabular}{|c|c|c|c|c|c|}
\hline $\mathbf{D}$ & M & PD & ID & IM & iPD \\
\hline $51.32^{*} \pm 0.329$ & $44.7 \pm 1.493$ & $49.3^{*} \pm 0.569$ & $44.56 \pm 0.3807$ & $52.73^{*} \pm 2.2554$ & $52.45^{*} \pm 0.5341$ \\
\hline
\end{tabular}

Average values followed by * are significant at $5 \%$ Tukey test, $\mathrm{P}<0.05$

Average values followed by $* *$ are highly significant at $1 \%$ Tukey test, $\mathrm{P}<0.01$

Uzarigenin

\begin{tabular}{|c|c|c|c|c|c|}
\hline D & $\mathbf{M}$ & PD & ID & IM & iPD \\
\hline $6.28 \pm 0.189$ & $13.76 * \pm 0.252$ & $11.54 * \pm 1.140$ & $15.003^{*} \pm 0.124$ & $13.94 * \pm 1.284$ & $12.55 * \pm 0.207$ \\
\hline
\end{tabular}

Average values followed by $*$ are significant at $5 \%$ Tukey test, $\mathrm{P}<0.05$

Average values followed by ** are highly significant at $1 \%$ Tukey test, $\mathrm{P}<0.01$

Uzarigenin di glycoside

Uzarigenin di glycoside
\begin{tabular}{|c|c|c|c|c|c|}
\hline D & M & PD & ID & IM & iPD \\
\hline $16.81^{*} \pm 0.189$ & $21.77^{* *} \pm 0.252$ & $17.52^{*} \pm 1.14$ & $14.09 * \pm 0.1244$ & $15.04 * \pm 1.2849$ & $7.9 \pm 0.207$ \\
\hline
\end{tabular}

*significant at $5 \%$ Tukey test, $(\mathrm{P}<0.05)$

**highly significant at $1 \%$ Tukey test $(\mathrm{P}<0.01)$

\section{Gene identification}

Through this study, we were able to characterize four genes related to pharmaceutical compounds production. flavonol oxygenase (KU997644) responsible for flavonol accumulation which is related to reduce risk of coronary heart disease mortality, stroke, hypertension and reduces C-reactive protein concentrations [37] [38] [39] [40]. Oxysterol-binding protein (KX002269) is used in atherosclerosis treatment [41] [42]. Calreticulin (KT943752), this protein plays a role to promote macrophages to engulf hazardous cancerous cells [43]. Amyrine synthase (KU997645) is responsible for amyrine accumulation which suggests that it led compound for drug development effective in diabetes and atherosclerosis [44]. $\alpha, \beta$-amyrine has the potential to combat acute pancreatitis in rats [45].

The characterization was done by using RNA-seq raw data. A total of 70,429,953 paird-end short RNA sequence reads were generated for $C$. procera using the HiSeq 2000 Illumina platform (Illumina, San Diego, CA). CLC genomic workbench program was used to perform genome sequencing and characterizing genes. Solanum tuberosum geraniol 8-hydroxylase XM 006355445.2 was used as a reference to characterize flavonol oxygenase, Sesamum indicum oxysterol-binding protein XM_011091183.1 was used as a reference to characterize oxysterol-binding protein, Catharanthus roseus amyrine synthase JQ027033.1 was used as a reference to characterize amyrine synthase and Medicago truncatula calreticulin XM 003624156.2 was used as a reference to characterize calreticulin in CLC genomic work-bench program. Phylogenetic tree was used to perform genes relationships (Fig. 6) were like those of previous analyses. 
Citation: S. Baabad et al.,2018. Effect of environmental conditions in accumulation of some pharmaceutical substances in Calotopis procera. Advances in Environmental Biology.12(12): 5-10.DOI:10.22587/aeb.2018.12.11.2

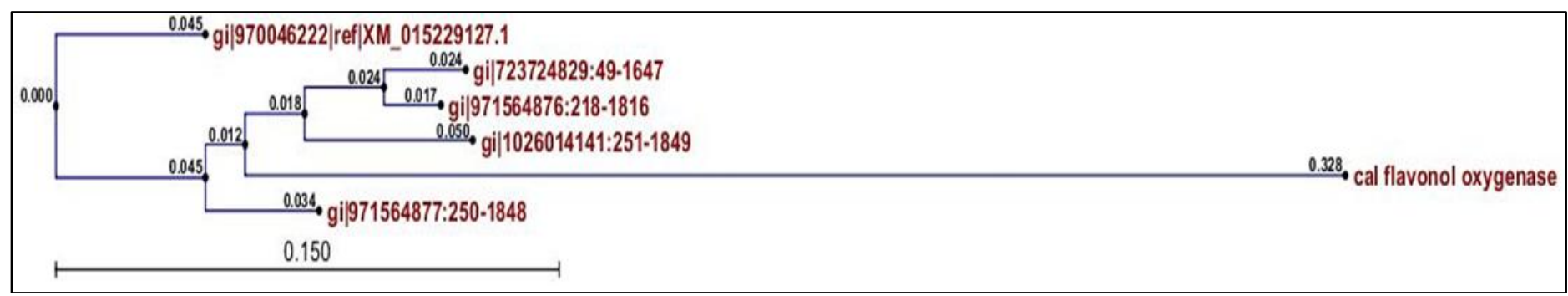

(A)

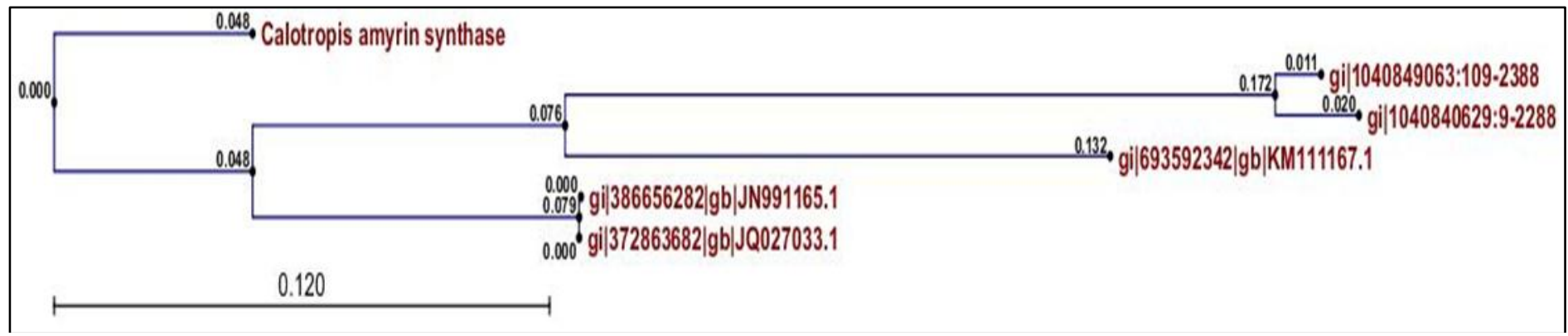

(B)

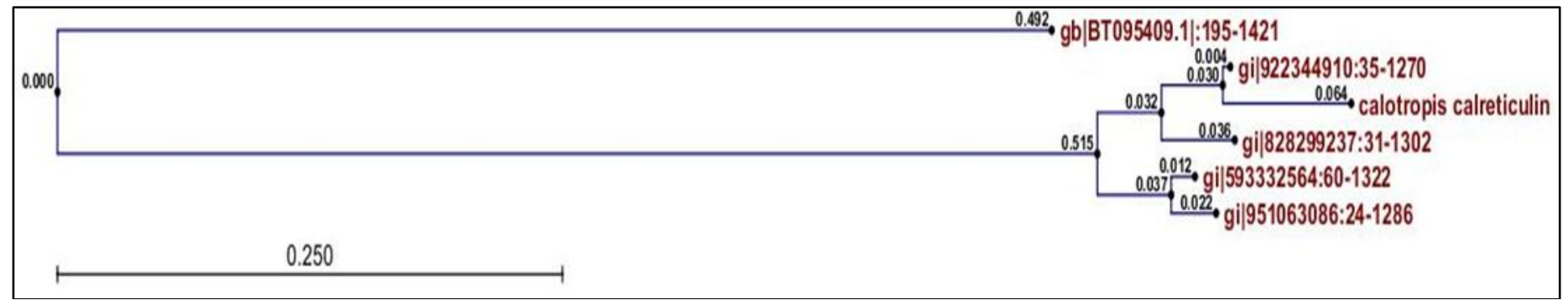

(C)

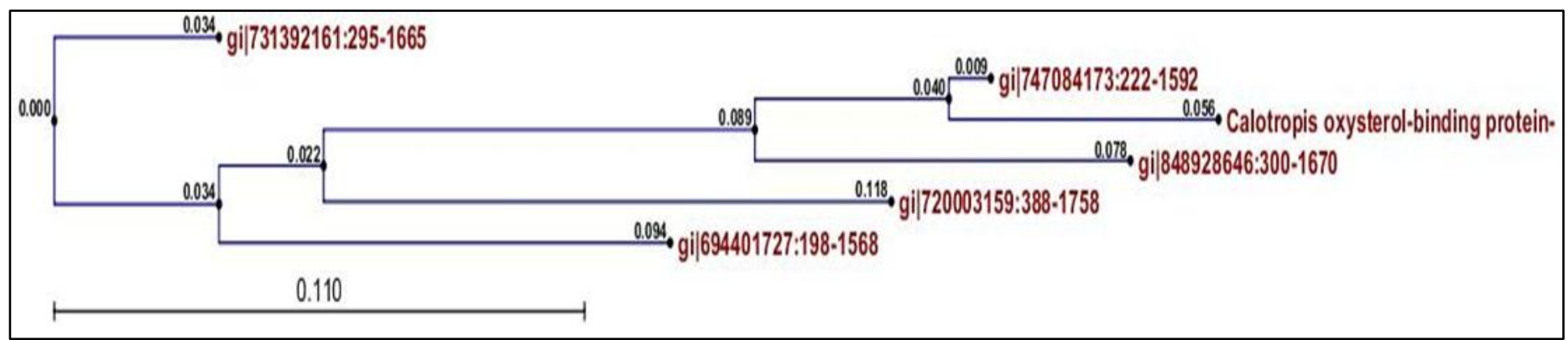

(D)

Fig. 6. Phylogenetic analysis of (A) 5 flavonol oxygenase sequences with the obtained $C$. procera flavonol oxygenase sequence, (B) 5 amyrine synthase sequences with the obtained $C$. procera amyrine synthase sequence, (C) 5 amyrine synthase sequences with the obtained $C$. procera amyrine synthase sequence, (D) 5 oxysterol-binding protein sequences with the obtained $C$. procera oxysterol-binding protein sequence.

\section{CONCLUSIONS}

In this study, we focused on detecting the suitable time to isolate some pharmaceutical compounds (Calotoxin, $\alpha$-amyrene and Uzarigenin) with high concentration in Calotropis procera. Given the importance of these glycosides in medicinal effects such as regulating heart contractions, Benign prostatic hyperplasia, antihyperglycemic effect, anti-inflammatory and antioxidant agent, our study gives chance provide opportunities for medical companies to know the suitable time to isolate a huge quantity of these components. Subsequently, saving a lot of efforts and money. Moreover, we succeeded in characterizing and identifying the gene responsible for amyrine accumulation (amyrine synthase accession no. KU997645). This finding facilitates amyrine production in vitro in huge amount using genetically modified organism. but Also, three genes involved in pharmaceutical compounds in Calotropis procera were identified, calreticulin (KT943752) which promotes macrophages to engulf hazardous cancerous cells, oxysterol-binding protein (KX002269) which is related to atherosclerosis treatment, and flavonol oxygenase (KU997644) responsible for flavonol accumulation which treats many diseases like reducing risk of coronary heart disease mortality, stroke, etc. Therefore, this study suggests that biologists efforts are needed to produce these compound in the lab via genetically modified organism, an approach that provides and facilitates a huge production with low price in the future.

\section{REFERENCES}

1. Aiton W. T. (2010). Germplasm Resources Information Network. United States

2. Lewis W, Elvin-Lewis M. (1977). Medical botany: plants affecting man's health. New York: John Wiley \& Sons Publications.

3. Oudhia P, Dixit A. (1994). Weeds in Ambikapur region (Madhya Pradesh) and their traditional use. Weeds News 1 (2): 19-21. 
4. Longanga OA, Vercruysse A, Foriers A. (2000). Contribution to the ethnobotanical, phytochemical and pharmacological studies of traditionally used medicinal plant in the treatment of dysentery and diarrhea in Lomela area, Democratic Republic of Congo (DRC). J. Ethnopharmacology 71: 411-423.

5. Ahmed KK, Rana AC, Dixit VK. (2005). Calotropis species (Ascelpediaceae), a comprehensive review. Pharmacognosy Magazine 1: 48-52.

6. Parrotta, J.A. (2001). Healing plants of Peninsular India. CAB International, Wallingford, UK and New York. p 944.

7. Khiralla A, Ietidal EM, Tzvetomira T, Herve S, Sophie S-D, Alain H, Philippe A, Gaelle C, Rosella S, Annelise L, Sakina Y, Dominique L-M (2016). Endophytic fungi associated with Sudanese medicinal plants show cytotoxic and antibiotic potential. FEMS Microbiology Letters, Vol. 363 , No. 11

8. Little, E.L., Jr., R.O. Woodbury, and F.H. Wadsworth. (1974). Trees of Puerto Rico and the Virgin Islands. Vol. 2. Agriculture Handbook 449. U.S Department of Agriculture, Washingtion, DC. p.1, 024.

9. Anver, S. and Alam M.M., (1992). Effect of latex seed dressing on interacting root-knot and reniform nematodes. Afro-Asian Journal of Nematology 2: $1-2,17-20$.

10. Charu-Jain and Trivedi P.C. (1997).Nematicidal activity of certain plants against root-knot nematode, Meloidogyne incognita, infecting chickpea, Cicer arietinum. Annals of Plant Protection Sciences 5(2): 171-174

11. Al-Yahya MA, Al-Meshal IA, Mossa JS, Al- Badr AA, Tarig M. (1990). Saudi plants: A phytochemical and biological approach. Riyadh: King Saud university press, Page 31- 34 .

12. Sabhi M, Ramezanian M, Jaffari G, Haravi G, Bahaeddini F and Aynehi Y (1985). Survey of Indian Plants for Saponins, Alkaloids, Flavonoids and Tannins, the Plant of Capparidaceae. Inte.J. Crude Drug Res., 23: 165-177.

13. Deepak D. (1995). The taxonomy and phytochemistry of the Asclepiadaceae in Tropical Asia. In: Ruthkiew, editor. UniversitiPertanian, Malaysia, 33.

14. Bryce TA, Eglinton G, Hamilton RJ, Martin-Smith M, and Subramanian G (1967). Triterpenoids from New Zealand plants-II: The triterpene methyl ethers of Cortaderia toetoe Zotov. Phytochemi. J. Vol. (6), Issu. 5, PP. 772-73.

15. Osman AM., El GarbyYounes M., Mokhter A. (1975). Chemical examination of local plant. Part Xlll. elucidation of the structure of new glycoside from the leaves of Egyptian Hibiscus sabdariffa. Aust. J. Chem., 28: 217-220.

16. Robinstan I., John Goad L., Clague ADH. and Mulheirn L.J. (1976). The 220 MHz NMR spectra of phytosterols. Phytochemi. J. Vol. 15, Issu. 1, PP. 195-200.

17. Mezzetti T, orzalesi G, and Bellarta V. (1971). Chemistry of Ursolic Acid. Planta Med J.; 20(5): 244-252.

18. Huneck S, Overton KH. (1971). Neue diterpenoide und andere inhaltsstoffe aus lebermoosen. Phytochemi. J.Vol. 10, Issu. 12, PP. $3279-3281$.

19. Singh B, and Rastogi RP. (1972). Structure of asclepin and some observations on the NMR spectra of Calotropis glycosides. Phytochemi.J. Vol. 11, Issu. 2 PP. 757-762.

20. Chopra RN.; Nayar SL.; and Chopra IC. (1956). Glossary of Indian Medicinal Plants, New Delhi, 46.

21. Rastogi RP, Mehrotra BN (1998). Rastogi RP and Mehrotra BN. Compendium of Indian Medicinal Plants. 2nd Reprint, Central Drug Research Institute, Lucknow and National Institute of Science Communication, Council of Scientific and Industrial Research, New Delhi Vol. 1: 434-436.

22. Ramadan Ahmed, Jamal S. M. Sabir, Saleha Y. M. Alakilli, Ahmed M. Shokry, Nour O. Gadalla,Sherif Edris, Magdy A. Al-Kordy, Hassan S. AlZahrani, Fotouh M. El-Domyati, Ahmed Bahieldin, Neil R Baker, LotharWillmitzer, Susann Irgang (2014). Metabolomic Response of Calotropis procera growing in the Desert to Changes in Water Availability. PLoS ONE 9(2): e87895.

23. Pandey A, Swarnkar V, Pandey T, Srivastava P, Kanojiya S, Mishra D K and Tripath V (2016). Transcriptome and Metabolite analysis reveal candidate genes of the cardiac glycoside biosynthetic pathway from Calotropis procera. Nat. Sci. Reports | 6:34464 | DOI: 10.1038/srep34464

24. Atal CK, Sethi PD. (1961). Proteolytic activity of some Indian plants. III. Pharmacological evaluation of calotropain from Calotropis procera. Indian J. Pharm, 24 (6): 131-134.

25. Malik NN, Chughati MID. (1979). Antimicrobial activity of Calotropis proceraa preliminary study, Pak. J. Sci, 31: 127-129.

26. Girdhar G, Devel K PK, Mittel P Vasudevan. (1984). Mosquito control by Calotropis latex, Pesticides, 18: 82-87.

27. Masood A, Haq S, Anjum SH, Saxena SK. (1980). Further studies on the effect of some plants extracts on the mortality of Maloidogyniin cognite, J. Sci. Res. Plants Med, 1: 18-22.

28. Ajoub SMH, Kingston DGI. (1981). Screening of plants used in Sudan folk medicine for anti-cancer activity, Fitoterapia, 52: $281-284$.

29. Dhar ML, Dhar MM, Dhawan BN, Mehrotra MN, Roy C. (1968). Screening of Indian plants for biological activity: part I, Indian J. Exp. Biol, 6: 231247.

30. Basu A, Chaudhury AKN. (1991). Preliminary studies on the anti-inflammatory and analgesic activities of Calotropis procera root extract. J. Ethnopharmacol, 31: 319-324.

31. Kwon CW, Park K-M, Kang B-C, Kweon D-H, Kim M-D, Shin SW, JeY H, Chang P-S (2015). Cysteine Protease Profiles of the Medicinal Plant Calotropis procera R. Br. Revealed by De Novo Transcriptome Analysis. PLoS ONE 10(3): e0119328. doi: 10.1371/journal.pone.0119328.

32. Ramadan Ahmed M., , Ahmed Abdel Azeiz, Saeed Baabad, Sameh Hassanein, Nour O. Gadalla, Sabah Hassan, Mardi Algandaby , Salwa Bakr , Thana Khan , Heba H. Abouseadaa , Hani Mohammed Ali , Areej Al-Ghamdi , Gamal Osman, Sherif Edris , Hala Eissa, Ahmed Bahieldin (2019).Control of $\beta$-sitosterol biosynthesis under light and watering in desert plant Calotropis procera. steroids,141, pp 1-8

33. Ramadan AM., Hassanein SE. (2014). Detection of P5CS gene in Calotropis procera plant from the de novo assembled transcriptome contigs of the high-throughput sequencing dataset. C. R. Biologies 337 (12) 683-690

34. Rasmann S. and Agrawal AA (2011). Latitudinal patterns in plant defence: evolution of cardenolides, their toxicity and inductionfollowing herbivory. Ecol. Lett. 14, 476-483.

35. Rasmann S., Agrawal AA. Cook SC. and Erwin AC (2009). Cardenolides, induced responses, and interactions between above- and belowground herbivores of milkweed (Asclepias spp.). Ecol. 90(9), 2393-2404.

36. Sun J., Xiao J., Wang X., Yuan X. and Zha, B. (2012). Improved cardenolide production in Calotropis gigantea hairy roots using mechanical wounding and elicitation. Biotechnol Lett. 34(3), 563-569.

37. Huxley RR, Neil HA. (2003). the relation between dietary flavonol intake and coronary heart disease mortality: a meta-analysis of prospective cohort studies. Eur J ClinNutr.57 (8):904-8.

38. Chun OK, Chung SJ, Claycombe KJ, Song WO. Serum (2008). C-reactive protein concentrations are inversely associated with dietary flavonoid intake in U.S. adults.JNutr. 138(4):753- 60.

39. Hollman PC, Geelen A, Kromhout D. (2010). Dietary flavonol intake may lower stroke risk in men and women. J Nutr.140 (3):600-4.

40. Cassidy A, Rimm EB, O'Reilly EJ, Logroscino G, Kay C, Chiuve SE, Rexrode KM. (2012). Dietary flavonoids and risk of stroke in women. Stroke, J.43 (4):946-51.

41. Olkkonen VM, Lehto M. (2004). Oxysterols and oxysterol binding proteins: role in lipid metabolism and atherosclerosis. Ann Med., 36(8):562-72.

42. Olkkonen VM. (2012). Macrophage oxysterols and their binding proteins: roles in atherosclerosis. Curr. Opin. Lipidol. 23(5):462-70.

43. Chao MP, Jaiswal S, Weissman-Tsukamoto R, Alizadeh AA, Gentles AJ, Volkmer J, Weiskopf K, Willingham SB, Raveh T, Park CY, Majeti R, Weissman IL (Dec 2010). Calreticulin is the dominant pro-phagocytic signal on multiple human cancers and is counterbalanced by CD47. Sci. Trans. Medicine, 2 (63): 63-94.

44. Flávia AS, Julyanne TF, Bruno RA, Tiago SM, Armenio ACAS, Gerly ACB, Mariana HC and Vietla SR.( 2012). Antihyperglycemic and hypolipidemic effects of $\alpha, \beta$-amyrine, a triterpenoid mixture from Protium heptaphyllum in mice. Lipids Health Dis.; 11: 98.

45. Caroline MM, Karine MMBC, Julliana Cde SN, Talita CM, Vietla SR, Flávia AS, Gerly ACB, and Mariana HC (2010). $\alpha, \beta$-amyrine, a natura triterpenoid ameliorates L-arginine-induced acute pancreatitis in rats. World J Gastroenterol,16 (34): 4272-4280. 